\title{
Prevalence of WIDAL Positivity in a Tertiary Care Hospital in Hyderabad, Telangana-A Retrospective Study
}

\author{
R. Shyamala ${ }^{1}$, Vibha Rani2 ${ }^{{ }^{*}}$ and D. Achut Rao ${ }^{1}$ \\ ${ }^{1}$ Department of Microbiology, ${ }^{2}$ Department of Pharmacology, Malla Reddy Medical College for \\ Women, Hyderabad, Telangana, India \\ *Corresponding author
}

\section{A B S T R A C T}

\begin{tabular}{|l}
\hline Ke y w o r d s \\
Widal test, \\
Typhoid, \\
Enterobacteriaceae, \\
MDR.
\end{tabular}

\section{Introduction}

Typhoid (enteric) fever caused by Salmonella typhi is an important cause of morbidity and mortality (Buckle et al., 2010; Mogasale et al., 2014). The situation is further complicated by increased incidence in some countries of S. Paratyphi A as a cause of enteric fever (Crump et al., 2004). While both diseases share clinical features, paratyphoid fever tends to have a more benign course of illness. Without effective treatment, typhoid fever has a case-fatality rate of $10-30 \%$. This number is reduced to $1-4 \%$ in those receiving appropriate therapy (Crump et al., 2004). Typhoid fever is endemic in India. The prevalence rate of typhoid in India is 88 cases/lac population and death due to typhoid is $0.029 /$ lakh population (Park, 2013). Risk factors include contaminated water or ice, flooding, food and drinks purchased from street vendors, raw fruits and vegetables grown in fields fertilised with sewage, illhoused contacts, lack of hand washing and toilet access and evidence of prior Helicobacter pylori (David et al., 2012). The disease occurs at all age groups but is probably most common in age group 520years (Ananthanarayan, 2013). Salmonellae are Gram negative rods from the family Enterobacteriaceae. They are motile, flagellate, non-sporulating and facultative anaerobic bacilli. It has three main antigens: somatic $\mathrm{O}$ antigen, surface Virulent $\mathrm{Vi}$ 
antigen and flagellar $\mathrm{H}$ antigen (Ananthanarayan, 2013). Human beings are the only reservoir host for typhoid fever and the disease is transmitted by the ingestion of food or water contaminated with faeces of infected persons which contain the bacteria (Mweu and Mike English, 2008). Signs and symptoms of enteric fever includes gradual onset of malaise, headache, nausea, vomiting, abdominal pain, rose spots, relative bradycardia, splenomegaly, abdominal distension and tenderness. Infection begins when organisms breach the mucosal epithelium of the intestine by transcytosis, an organism mediated transport process through the cell via an endocytic vesicle. Having crossed the epithelial barrier, organisms invade and replicate in macrophages in Peyer patches, mesenteric lymph nodes and the spleen.

Bacteraemia occurs and the infection then localizes principally in the lymphoid tissue of the small intestine. Peyer patches become inflamed and may ulcerate, with involvement greatest during the third week of the disease. Complications include intestinal hemorrhage or intestinal perforation. Appearance of leukocytosis and tachycardia should suggest these complications. Urinary retention, pneumonia, thrombophlebitis, myocarditis, psychosis, cholecystitis, nephritis, osteomyelitis and meningitis are less often observed (Brain S. Schwartz, 2016).

Bacteriological diagnosis of enteric fever consists of isolation of the bacilli from the patient and demonstration of antibodies in the patient's serum. The Widal test has been used very extensively in the serodiagnosis of typhoid fever. It is used to measure agglutinating antibodies against $\mathrm{H}$ and $\mathrm{O}$ antigens of Salmonella typhi. Widal test remains one of the best, easily accessible, cheap and simple methods in comparison to other molecular and biochemical test for the diagnosis of typhoid fever. However, the major drawback of the Widal test is its cross reactivity with some other bacteria of the same genus (Aziz and Haque, 2012). Culture media most commonly employed are Mac Conkey, DCA and Wilson -Blair media. Bone marrow culture is $55-90 \%$ sensitive. Culture of intestinal secretions can be positive despite negative bone marrow culture. PCR and DNA probe assays to detect $S$. typhi in blood have been identified but not yet been developed for clinical use.

The need for an alternative, low cost test for typhoid has also spurred the development of other serological assays including counter immune electrophoresis (Tsang and Cahu, 1981), ELISA (Beasley et al., 1981), RIA (Chau et al., 1981) and haemagglutination assay (Coovadia et al., 1986).

Preventive immunization includes multiple dose oral vaccine and a single dose parenteral vaccine. Their efficacies are similar, but oral vaccine causes fewer side effects. Boosters, when indicated, should be given every 5 years and 2years for oral and parenteral preparations, respectively. Adequate waste disposal and protection of food and water supplies from contamination are important public health measures to prevent Salmonellosis.

Treatment includes Fluoroquinolones such as Ciprofloxacin $750 \mathrm{mg}$ orally twice daily or Levofloxacin $500 \mathrm{mg}$ orally once daily, 5-7 days for uncomplicated enteric fever and 1014 days for severe infection have become the agents of choice for treatment of Salmonella infections. Ceftriaxone, $2 \mathrm{~g}$ intravenously for 7 days, is also effective. Although resistance to Fluoroquinolones or Cephalosporins occurs uncommonly, the prevalence appears to be increasing. When an infection is caused by a multidrug-resistant strain, select an antibiotic to which the isolate is susceptible in vitro. 
Alternatively, increasing the dose of Ceftriaxone to $4 \mathrm{~g} /$ day and treating for 10-14 days or using Azithromycin $500 \mathrm{mg}$ orally for 7 days in uncomplicated cases may be effective. In years past, Ampicillin, Chloramphenicol, and TrimethoprimSulfamethoxazole had been effective treatments but resistance has spread globally. Treatment of carriers is often unsuccessful in eradicating the carrier state.

Ciprofloxacin, $750 \mathrm{mg}$ orally twice a day for 4 weeks, has proved to be highly effective. Cholecystectomy may also achieve this goal (Brain S. Schwatz, 2016). Multi Drug Resistant (MDR) strains of $S$. typhi are common. These strains contain plasmids encoding resistance to Chloramphenicol, Ampicillin and Trimethoprim antibiotics long used to treat enteric fever. Ceftriaxone, Cefotaxime and oral Cefixime are effective for treatment of MDR enteric fever including Naldixic acid resistant (NAR) and Fluroquinolone resistant strains (David et al., 2012). In our study, we describe the prevalence and the demographic pattern of typhoid fever reported from a tertiary care hospital located at Hyderabad, Telangana.

\section{Materials and Methods}

This study was conducted in the Department of Microbiology, Malla Reddy Medical College for Women, Hyderabad, Telangana. The duration of sample collection was for 6 months i.e. from January 2017 to June 2017. The study includes all age groups and both genders. Informed consent was taken from the patients before taking blood sample. Blood samples were collected from the patients who came with the history of fever and a provisional clinical signs and symptoms of typhoid fever. Sterile test tubes were used to store the blood which was collected from the patient. The tubes with the samples were kept aside for 15 minutes at room temperature to allow clotting of blood. After clotting the blood, samples were centrifuged at 3000rpm for 15 minutes to obtain clear serum. The Widal tube agglutination test was done on all sera by the conventional agglutination method using commercially available antigens (TULIP Diagnostic Private Limited). $0.4 \mathrm{ml}$ of two fold serially diluted patients sera (dilution from $1: 20$ to $1: 320$ ) in $0.9 \%$ normal saline were tested by adding an equal volume of antigen. A negative saline control was included in each batch of the test to check for auto agglutination.

A diagnostic titre of more or equal to 1:80 suggests positive test. Data which was collected was entered in to Microsoft excel sheet and was compiled and analyzed by statistical method of frequency and percentage.

\section{Results and Discussion}

A total number of 7800 samples were tested in this hospital, during the study period i.e. from January 2017 to June 2017 for the suspected cases of typhoid fever. Widal test was done on all samples and total number of positive Widal cases obtained was 763 so the overall prevalence rate of typhoid fever from our study is $9.7 \%$.

Of the 763 positive cases, 397 (52\%) were from males and $366(47.9 \%)$ were from females (Table 1 and Figure 1). The maximum number of typhoid positive cases were reported from the month of April, May $(39.5 \%)$ and minimum number of positive cases were from February month (12.3\%) (Table 2 and Figure 2). In our study maximum affected age group was $0-10$ years $(57.1 \%)$ and minimum affected age group was 71-80 years (Table 3 ). 
Table.1 Gender wise distribution of typhoid positive cases reported between January 2017 and June 2017

\begin{tabular}{|l|l|}
\hline Males & 397 \\
\hline Females & 366 \\
\hline Total & 763 \\
\hline
\end{tabular}

Table.2 Month wise distribution of typhoid positive cases reported between January 2017 and June 2017

\begin{tabular}{|l|l|}
\hline January & 121 \\
\hline February & 94 \\
\hline March & 106 \\
\hline April & 157 \\
\hline May & 145 \\
\hline June & 140 \\
\hline
\end{tabular}

Table.3 Age wise distribution of typhoid positive cases re reported between January 2017 and June 2017

\begin{tabular}{|l|l|}
\hline Age group (in years) & No. of positive cases \\
\hline $\mathbf{0 - 1 0}$ & 436 \\
\hline $\mathbf{1 1 - 2 0}$ & 186 \\
\hline $\mathbf{3 1 - 4 0}$ & 41 \\
\hline $\mathbf{4 1 - 5 0}$ & 24 \\
\hline $\mathbf{5 1 - 6 0}$ & 10 \\
\hline $\mathbf{6 1 - 7 0}$ & 8 \\
\hline $\mathbf{7 1 - 8 0}$ & 1 \\
\hline
\end{tabular}

Fig.1 Graph representing typhoid positive cases among males and females

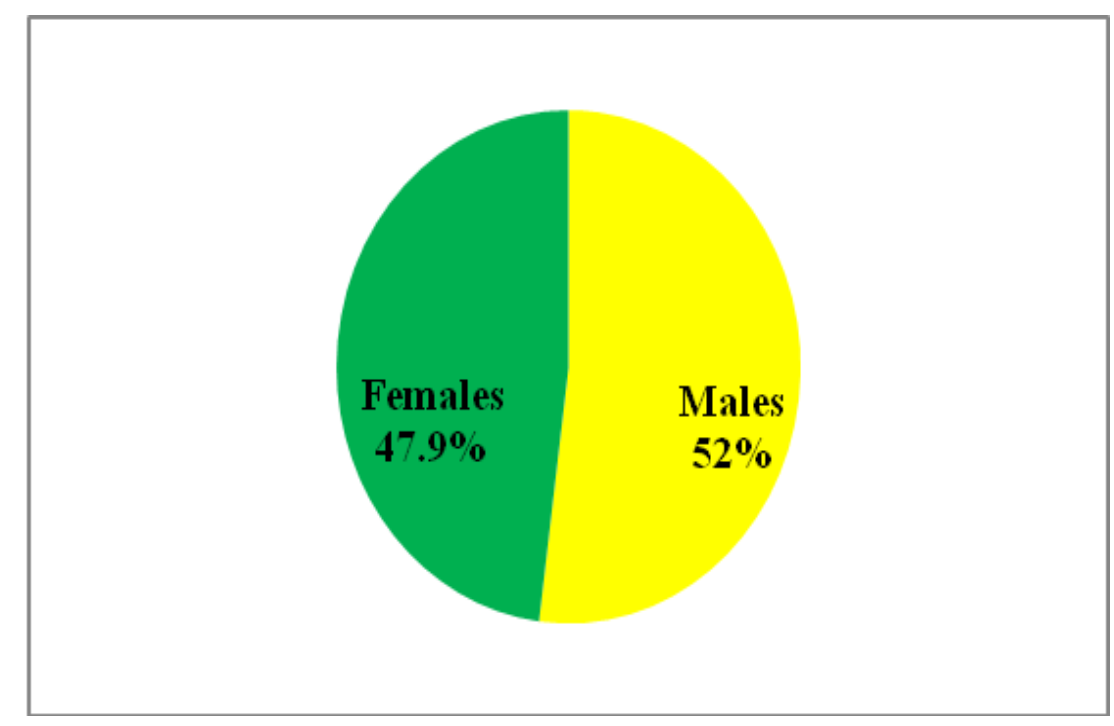


Fig.2 Month wise distribution of typhoid positive cases

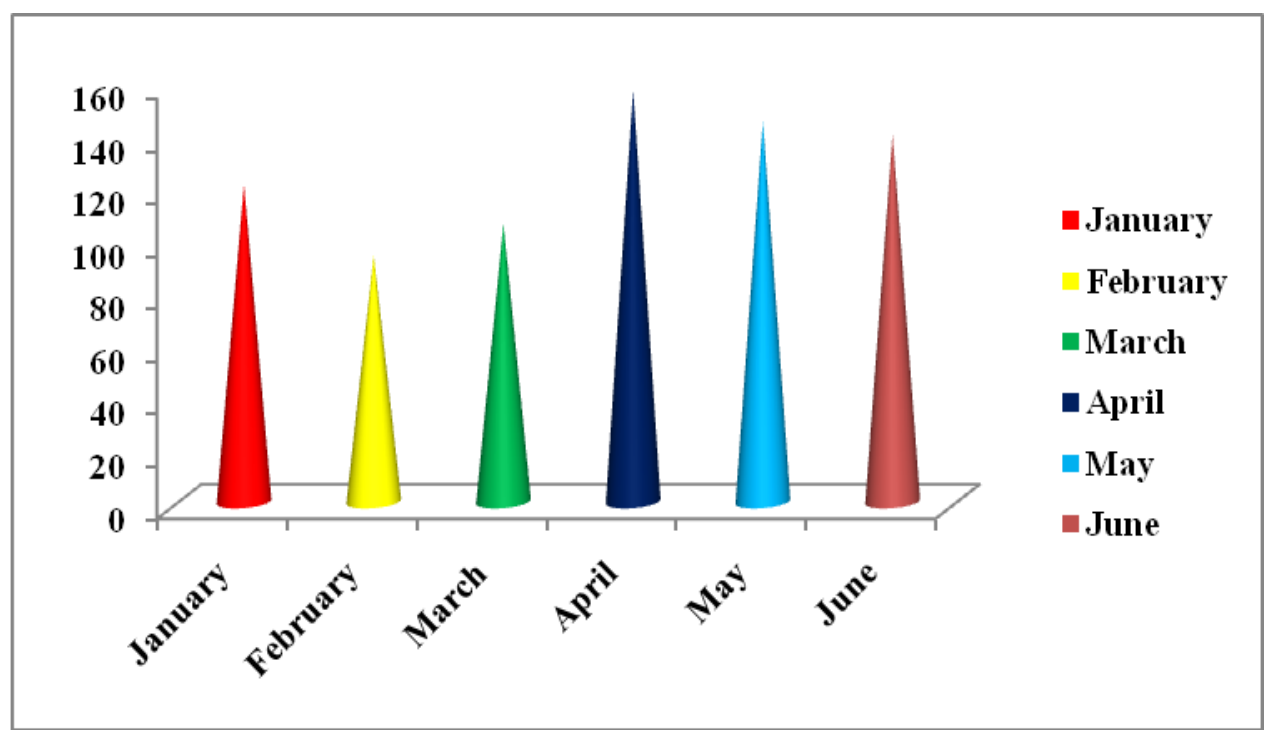

A total number of 7800 samples were tested in this hospital for typhoid fever, of which positive Widal cases were 763 and the overall prevalence of typhoid fever is $9.7 \%$. In our study the cases of typhoid fever was more among males $(52 \%)$ than in females $(47.9 \%)$. This finding is similar to studies done by Desai and Vijapura (2015) and in contrast to studies done by Jitendra Sharma and Mridul Malakar (2013) and Manjit Chaudhary et al., (2016). Where typhoid positive cases were more among females than in males. Our study indicates a high incidence of typhoid fever in children below 10 years $(57.1 \%)$.

This finding is in contrast with other studies, were incidence of typhoid was $67.1 \%$ and $85.4 \%$ in $0-10$ years age group (Desai and Vijapura, 2015; Manjit Chaudhary et al., 2016). After age of 20 years, the incidence falls probably due to acquisition of immunity from clinical and subclinical infection.

The high disease burden in children in our area highlights the importance of implementation of vaccine at early age as well as improvement in water sanitation and hygiene. Protection and purification of drinking water supplies, improvement of basic sanitation and promotion of food hygiene are essential measures to interrupt transmission of typhoid fever. Immunization against typhoid does not give 100 per cent protection, but it definitely lowers both the incidence and seriousness of the infection (Park, 2013).

It was observed that a large number, 302 $(39.5 \%)$, of the cases of enteric fever clustered in the hot months of April, May. During summer, poor water supply, sanitation systems and increased fly menace can account for the higher incidence of typhoid fever cases in these months.

In conclusion, Diagnosis of typhoid fever on an early is of therapeutic value otherwise it would result in fatal complications.

Appropriate treatment of water and maintaining good sanitation methods will definitely help in preventing this infection.

As the prevalence of typhoid fever was more among children in this study, immunization against typhoid will definitely reduce the seriousness and prevent this infection among children. 


\section{References}

Ananthanarayan, Paniker. Enterobacteriaceae III: Salmonellosis. Textbook of Microbiology. $9^{\text {th }}$ ed. Universities Press, India; 2013: 290-92.

Aziz, T., S S Haque. Role of Widal test in the diagnosis of typhoid fever in context to other test. American Journal of Biochemistry 2012; 2(1):16-18.

Beasley, W.J., Joseph SW, Weiss E.Improved serodiagnosis of Salmonella enteric fevers by an enzyme linked immunosorbent assay. J.Clin.Microbiol 1981; 13(1):106-14.

Brain S. Schwartz, Bacterial and Chlamydial infections. In: Maxine A Papadakis, Stephen J. Mc Phee.Current Medical Diagnosis and Treatment. $55^{\text {th }}$ ed. New York, NY: McGrawHill; 2016:1443-44.

Buckle, G.C., Walker CL, Black RE. Typhoid fever and paratyphoid fever: Systematic review to estimate global morbidity and mortality for 2010. J Glob Health 2012; 2(1):010401.

Chau, P.Y., RSW Tsang, SK Lam, JT La Brooy, D Rowley. Antibody response to the lipopolysacharide and protein antigens of Salmonella typhi during typhoid infection. II Measurement of intestinal antibodies by radioimmunoassay. Clin. Exp.Immunol 1981; 46:515-20.

Coovadia, Y.M., Singh V, Bhana RH, Moodley N. Comparison of passive haemagglutination test with Widal aggluyination test for serological diagnosis of typhoid fever in an endemic area. J.Clin. Pathol.1986; 39; 680-83.

Crump, J.A., Luby SP, Mintz ED. The global burden of typhoid fever. Bull World Health Organ 2004; 82(5):346-53.

Crump, J.A., Mintz ED. Global Trends in Typhoid and Paratyphoid Fever. Clinical Infectious Diseases 2010;50(2):241-46.
David A. Pegues, Samuel I. Miller. Salmonellosis. Harrisons Principles of Internal Medicine. $18^{\text {th }}$ ed. New York, NY: McGraw-Hill; 2012:127476.

Desai, P., Vijapura A.Y. Profile of typhoid fever in admitted paediatric patients from tertiary care hospital. International Journal of Paediatric Research 2015; 2(4):75-79.

Jitendra Sharma, Mridul Malakar. Int J Res Dev Health 2013; 1(3):109-14.

Kinikar Anagha, Bhalerao Deepika, Roushani Shahriar, Kulkarni Sanjeev. Typhoid in pediatric age group in a rural tertiary care centre: present scenario. Int.J.Curr.Microbiol.App.Sci 2015; 4(1):16268.

Manjit Chaudhury, Mridul Malakar, Sibarani Thinsin. Typhoid positivity subjects reported by a tertiary care Hospital of Goalpara district Indian Journal of Basic and Applied Medical Research 2016;5(3):66-71.

Mogasale, V., Maskery B, Ochiai RL, Lee JS, Mogasale VV, Ramani E. Burden of typhoid fever in low-income and middle-income countries: a systematic, literature-based update with risk-factor adjustment. Lancet Global Health 2014; 2(10):e570-80.

Mweu, E., Mike English. Typhoid fever in children in Africa. Tropical Medicine and International Health 2008; 13(4):532-40.

Park, K., Typhoid fever. Parks text book of Preventive and Social Medicine. $22^{\text {nd }}$ ed. M/s Banarsidas Bhanot Publishers India; 2013.213-16.

Tsang, R.S., P Y Cahu. Serological diagnosis of typhoid fever by counter immune electrophoresis. $\quad \mathrm{Br} \quad$ Med J.1981; 282(6275):1505-07.

\section{How to cite this article:}

Shyamala, R., Vibha Rani and Achut Rao, D. 2017. Prevalence of Widal Positivity in a Tertiary Care Hospital in Hyderabad, Telangana-A Retrospective Study. Int.J.Curr.Microbiol.App.Sci. 6(9): 2139-2144. doi: https://doi.org/10.20546/ijcmas.2017.609.263 